\title{
The effects of comprehensive nursing interventions on sexual functions in young and middle-aged patients with coronary stent implantation
}

\author{
Hong Zhang ${ }^{1}$, Gehui Zhu ${ }^{2}$, Jun Chen $^{3^{*}}$ \\ ${ }^{1}$ Department of Nursing, University Hospital of Hubei University for Nationalities, Enshi, China \\ ${ }^{2}$ Dongguan Tungwah Hospital, Dongguan, China \\ ${ }^{3}$ Department of Infertility and Sexual Medicine, The Third Affiliated Hospital, Sun Yat-Sen University, Guangzhou, China; \\ *Corresponding Author: mouds@,126.com
}

Received 20 July 2013; revised 21 August 2013; accepted 17 September 2013

Copyright (C) 2013 Hong Zhang et al. This is an open access article distributed under the Creative Commons Attribution License, which permits unrestricted use, distribution, and reproduction in any medium, provided the original work is properly cited.

\begin{abstract}
Objective: To study the effects of comprehensive nursing interventions on sexual functions in young and middle-aged patients with coronary stent implantation. Methods: 96 cases of coronary stent implantation were randomly divided into control group and intervention group (experimental group) with each group of 48 cases. The control group received the routine nursing measures after the coronary stent implantation and the experimental group was treated by the comprehensive nursing interventions such as psychological nursing, education of sexual knowledge, playing the full enthusiasm of spouse and appropriate exercise therapy on basis of the routine nursing measures. The two groups were given the questionnaire of brief male sexual function questionnaire (BSFI), Chinese patients with premature ejaculation sexual function score (C-ISFPE) and the international index of erectile function (IIEF-5). The scores of BSFI, C-ISFPE and IIEF-5 were compared between the two groups. Results: There were 29 cases who were satisfied with sexual life on the whole ( $\leq 1), 26$ cases with different degrees of premature ejaculation symptoms and 21 cases with erectile dysfunctions, which were respectively $27.08 \%, 30.2 \%$ and $21.87 \%$ of the total number. The scores of BSFI, C-ISFPE and IIEF-5 in the experimental group were significantly increased after the interventions $(P<0.05)$. The BSFI scores of the experimental group were significantly higher than those of the control group $(P<0.05)$ and the C-ISFPE and IIEF-5
\end{abstract}

scores in the two groups were significantly different $(P<0.05)$. Conclusions: The comprehensive nursing interventions can effectively improve the sexual functions and enhance the quality of life of young and middle-aged patients with coronary stent implantation.

Keywords: Coronary Heart Disease; Coronary Stent Implantation; Sexual Dysfunctions; Comprehensive Nursing Interventions

\section{INTRODUCTION}

The coronary heart disease is one of the serious diseases endangering human health and the onset age has been younger. As a kind of advanced medical treatment, the coronary stent implantation can help to reduce the rate of acute coronary occlusion and restenosis and has become the main means of coronary interventions [1]. The principal purpose of the coronary stent implantation is to improve the patient's quality of life, while the quality of sexual life is an important part in our life, especially for the young and middle-aged persons. But some patients believe that the sexual life after coronary interventions will increase the burden on the heart and result in more anxiety or fear because of the recurrence of heart disease. The research has shown that more than half of patients are not satisfied with their sexual life after coronary stent implantation owing to the lack of relevant knowledge and guidance [2]. According to Kostis' research, more than $60 \%$ of patients doubted about when and how to keep on their sexual life when they left the hospital [3]. At present, the study concerning sexual life of patients with the coronary stent implantation mainly focused on the investigation $[4,5]$, but the interventional 
studies were rarely reported. This study adopts the comprehensive nursing interventions and compares the changes of indexes for patients' sexual functions before and after the interventions in order to provide a scientific basis for improving the life quality of patients with coronary stent implantation.

\section{OBJECTS AND METHODS}

\subsection{Objects}

We applied the sampling method to select 90 married male patients treated by the coronary stent implantation from January 2007 to June 2009 in our hospital. Their spouses were aged 33 to $54(45.26 \pm 10.92$ on average). To literacy, there were 40 cases with primary school or junior school levels, 35 cases with high school or technical secondary school levels and 21 cases with university and above levels. The selected patients excluded the cases of unstable or refractory angina pectoris, uncontrolled hypertension, prostate diseases, sexual dysfunctions before operation and other organic diseases. The 96 cases were randomly divided into experimental group and control group with each group of 48 cases. The groups were comparable because the patients' information such as age, operation time and grades of cardiac functions were in no significant difference $(P>0.05)$.

\subsection{Intervention Methods}

The control group accepted the routine postoperative nursing and education after operation. The intervention group took the sexual knowledge on the basis of routine postoperative nursing and education, including: 1) To eliminate the anxiety of patients. Most patients concerned that the sexual life would send recrudescence of diseases and sudden death. So the patients and their spouse were informed that the ratio of sudden cardiac death during sexual life was less than $2 \%$ and the recurrent myocardial infarction was not directly related to sexual life. The psychological counseling was provided according to the patients' information such as age, work and family. 2) Sexual education for patients and their family. The handbooks about sexual knowledge after coronary stent implantation and individual psychological counseling were provided. Besides, monthly seminars or lectures were regularly held. The patients and their spouse had to learn the knowledge about recovery of sexual life after operation and do exercises before sexual life and pay attention to the frequency, body positions and special considerations (including avoiding sexing after a meal, drink or extramarital sex). 3) To play the full enthusiasm of spouse. The anxiety, fear and depression of patients due to the operation led to decrease sexual functions, so the spouse should strive to be considerate, comfort them and reduce the times of sexual life to help them regain confidence. 4) To carry out exercise therapy. As to the ways and amount of exercise, the nursing staff should give guidance for patients. The reasonable and moderate exercises can improve heart functions, enhance the body's resistance to various diseases and benefit the sex life.

\subsection{Investigation Methods}

The staff with special training granted the questionnaires to patients before intervention and six months after intervention respectively. The valid questionnaire would be taken back as soon as the patients finished independently. The questionnaires included the brief male sexual function questionnaire (BSFI) [6], Chinese patients with premature ejaculation sexual function score (C-ISFPE) [7] and the international index of erectile function (IIEF-5) [8]. The BSFI included 5 dimensions: sexual desires (2 entries), erectile functions (3 entries), ejaculatory functions (2 entries), awareness of sexual functions ( 3 entries) and overall satisfaction (1 entry). Each entry contained 5 options. If we kept scoring by 5 grades at the point from 0 to 4 and the score of overall satisfaction was less than or equal to $1(\leq 1)$, it was the low degree. The C-ISFPE was consisted of 10 questions, which was divided into 5 grades, keeping scoring from 0 to 4 . The premature ejaculation were the mild $(31-40)$, moderate $(16-30)$ and severe $(5-15)$. The lower the scores indicated, the heavier premature ejaculation symptoms performed. The IIEF- 5 contained 5 questions, scoring from 0 to 5 . The erectile dysfunctions also were the mild (21 - 12), moderate ( 8 - 11) and severe (5 - 7). The lower the scores indicated, the heavier erectile dysfunctions performed.

\subsection{Statistical Methods}

The SPSS16.0 software was used for descriptive statistics and randomized block designs Friedman test. There were significant differences $(P<0.05)$.

\section{RESULTS}

\subsection{Comparisons of BSFI Scores}

Before the intervention, the BSFI scores of the two groups showed no significant difference $(P>0.05)$. The BSFI scores of the experimental group after the intervention were significantly increased $(P<0.05)$ and the BSFI scores of experimental group were obviously higher than those of the control group $(P<0.05)$ (see Table 1).

\subsection{Comparisons of C-ISFPE and IIEF-5 Scores}

Before the intervention, there was no significant differences between C-ISFPE and IIEF-5 scores of the two 
Table 1. Comparisons of BSFI scores in the two groups before and after the interventions $(\bar{x} \pm s)$.

\begin{tabular}{|c|c|c|c|c|c|}
\hline Groups & $\begin{array}{l}\text { Sexual } \\
\text { desires }\end{array}$ & $\begin{array}{l}\text { Erectile } \\
\text { functions }\end{array}$ & $\begin{array}{l}\text { Ejaculatory } \\
\text { functions }\end{array}$ & Awareness & $\begin{array}{c}\text { Overall } \\
\text { satisfaction }\end{array}$ \\
\hline before & $2.7 \pm 0.8$ & $5.7 \pm 0.1$ & $4.4 \pm 0.5$ & $3.7 \pm 0.2$ & $1.1 \pm 0.2$ \\
\hline after & $2.9 \pm 0.6$ & $6.1 \pm 0.4$ & $4.9 \pm 0.7$ & $3.9 \pm 0.5$ & $1.2 \pm 0.1$ \\
\hline before & $2.7 \pm 0.7$ & $5.6 \pm 0.2$ & $4.5 \pm 0.3$ & $3.8 \pm 0.1$ & $1.2 \pm 0.2$ \\
\hline${ }^{2}$ after & $3.8 \pm 0.5^{\mathrm{a}, \mathrm{b}}$ & $7.2 \pm 0.3^{\mathrm{a}, \mathrm{b}}$ & $5.4 \pm 0.7^{\mathrm{a}, \mathrm{b}}$ & $4.5 \pm 0.3^{\mathrm{a}, \mathrm{b}}$ & $1.9 \pm 0.1^{\mathrm{a}, \mathrm{b}}$ \\
\hline
\end{tabular}

${ }^{a}$ The comparison to that before the intervention $(P<0.05)$; ${ }^{\mathrm{b}}$ the comparison to the control group $(P<0.05) ; 1=$ the control group, $2=$ the experimental group.

groups $(P>0.05)$. After the intervention, the C-ISFPE and IIEF-5 scores of the experimental group were significantly increased $(P<0.05)$ and the difference between C-ISFPE and IIEF-5 scores of the two groups were significant $(P<0.05)$ (see Table 2$)$.

\section{DISCUSSION}

The statistical data by WHO in 2010 show that approximately 17 million persons have died from coronary heart diseases each year around the world and the onset age has been younger [9]. The survival rate of acute myocardial infarction and angina pectoris patients has been greatly improved due to the development of interventional technology, but how to improve their quality of life after interventions is the key of nursing researches. The quality of sexual life is an important part of our life for concern. There have been only a few studies on sexual health of patients with the coronary stent implantation because of a long tradition. The majority of clinical studies have been limited to descriptive researches. The research by Wang Xin [4] showed that more than $80 \%$ patients of coronary heart disease were not familiar with the knowledge about safe sex after operation and $40 \%$ $70 \%$ of patients of acute myocardial infarction were faced with many problems such as sexual disorder and the decline in quality of life. The results of this study also showed that for the 96 cases, there were 29 cases whose score of overall satisfaction was less than or equal to 1 $(\leq 1)$, accounting for $30.2 \%$. 26 cases had different degrees of premature ejaculation symptoms, about $27.08 \%$ and 21 cases suffered from erectile dysfunctions, about $21.87 \%$. For the young and middle-aged patients with coronary heart diseases, the problem of sexual life of the patients with coronary heart disease has drawn attention of nursing staff and society around the world [4,10,11].

This study showed that the scores of BSF, C-ISFPE and IIEF-5 in the experimental group were significantly increased after comprehensive nursing interventions, which were proved to improve the sexual dysfunctions. Because some patients with coronary stent implantation
Table 2. Comparisons of C-ISFPE and IIEF-5 scores in the two groups before and after the interventions.

\begin{tabular}{cccc}
\hline \multicolumn{2}{c}{ Groups } & C-ISFPE & IIEF-5 \\
\hline \multirow{2}{*}{1} & before & $11.09 \pm 3.53$ & $9.05 \pm 3.17$ \\
& after & $13.10 \pm 3.25$ & $12.09 \pm 4.18$ \\
\multirow{2}{*}{2} & before & $11.42 \pm 3.87$ & $9.45 \pm 3.90$ \\
& after & $15.76 \pm 3.54^{\mathrm{a}, \mathrm{b}}$ & $14.05 \pm 4.70^{\mathrm{a}, \mathrm{b}}$ \\
\hline
\end{tabular}

${ }^{\mathrm{a}}$ The comparison to that before the intervention $(P<0.05)$; ${ }^{\mathrm{b}}$ the comparison to the control group $(P<0.05) ; 1=$ the control group, $2=$ the experimental group.

were in lack of relevant sexual knowledge and guidance, they were worried with recurrence of heart diseases and feared about sexual life, which resulted in the decline in sexual desires, frequency and lower sexual satisfaction. In this study, we took some effective measures such as distributing brochures, giving lectures and individual counseling to urge the patients to know the professional knowledge about sexual life and get over the nervousness and fear. These measures played an effective role in postoperative recovery of sexual life and improving the quality of life. In a word, the comprehensive nursing interventions can effectively improve the sexual dysfunctions and the life quality of the patients.

\section{REFERENCES}

[1] Zhang, H. (2010). Study on the relationship between health behavior and social support in patients underwent coronary artery stent implantation. Modern Preventive Medicine, 37, 4643-4649.

[2] Lunelli, R.P., Rabello, E.R., Stein, R., et al. (2008) Sexual activity after myocardial infarction: Taboo or lack of knowledge? Arquivos Brasileiros de Cardiologia, 90, 156-159.

[3] Ostis, J.B., Jackson, G., Rosen, R., et al. (2005) Sexual dysfunction and cardiac risk (the second Princeton consensus conference). American Journal of Cardiology, 96, 313-321.

[4] Wang, X., Wang, L.Z. and Li, J.H. (2008) A study on sex activity of male patients with coronary artery disease after coronary stent implantation. Nursing Journal of Chinese People's Liberation Army, 25, 29-33.

[5] Kong, X.P., Zhang, H.Y., Shen, Y.Z., et al. (2010) Research on the present situation and health education of coronary heart disease's sexual life. Chinese Journal of Nursing, 45, 1039-1042.

[6] O'Leary, M.P., Rhodes, T., Girman, C.J., et al. (2003) Distribution of the brief male sexual inventory in community men. International Journal of Impotence Research, 15, 185-191. http://dx.doi.org/10.1038/sj.ijir.3900996

[7] Yuan, Y.M., Xin, Z.C., Jin, T.Y., et al. (2003) Chinese index of sexual function for premature ejaculation (C1PE): A multidimensional scale for assessment of premature ejaculation. Chinese Journal of Andrology, 17, 302-306. 
[8] Lim, T.O., Das, A., Rampal, S., et al. (2003) Cross-cultural adaptation and validation of the English version of the International Index of Erectile Function (IIEF) for use in Malaysia. International Journal of Impotence Research, 15, 329-336. http://dx.doi.org/10.1038/sj.ijir.3901009

[9] World Health Organization (2010) The Atlas of heart disease and stroke $[\mathrm{EB} / \mathrm{OL}]$

http:/www.who.int/cardiovascular_diseases/resources/atl as/en

[10] Ivarsson, B., Fridlund, B. and Sjoberg, T. (2009) Informa- tion from health care professionals about sexual function and coexistence after myocardial infarction: A Swedish national survey. The Journal of Heart and Lung, 38, 330335. http://dx.doi.org/10.1016/i.hrtlng.2009.01.001

[11] Ebrahim, S., May, M., Ben Shlomo, Y., et al. (2002) Sexual intercourse and risk of ischaemic stroke and coronary heart disease:the Caerphilly study. Journal of Epidemiology \& Community Health, 56, 99-102. http://dx.doi.org/10.1136/jech.56.2.99 